\section{Effect of d-length and magnitude of immediate reward in partial delay}

JOSEPH A. SGRO, BRUCE D. MOORE, and JOHN $R$. SHOWALTER, Virginia Polytechnic Institute, Blacksburg, $\mathrm{Va}$. 24061

Resistance to extinction was studied as a function of successive delayed trials (D length) and reward magnitude on immediately rewarded (I) trials in a partial delay schedule. $D$ length produced greater resistance to extinction, but reward magnitude on I trials had no effect. The results were discussed in relation to Capaldi's sequential hypothesis.

A partial delay of reward schedule consists of a series of trials in which reward is immediately (I) available on some trials and delayed (D) on other trials. A recent contention (Capaldi, 1967b) is that as magnitude of reward is increased on I trials and is held constant on $\mathrm{D}$ trials during acquisition, the stimulus trace $\left(S^{D}\right)$ persisting from preceding $D$ trials should acquire greater associative strength with the instrumental response resulting in subsequent greater resistance to extinction. This contention was supported by Capaldi, Godbout, \& Downs (1968). It furthermore has been shown that the longer the succession of D trials (D length), the greater the resistance to extinction (Capaldi, 1967a). The present research sought to investigate the hypothesis that if $D$ length and reward magnitude on I trials were simultaneously increased during acquisition, resistance to extinction would be facilitated.

\section{SUBJECTS}

The Ss were 64 male albino rats obtained from Dublin Farms, Dublin, Virginia, and were 90-100 days old at the beginning of the experiment. One $S$ died during the course of the experiment.

\section{APPARATUS}

The apparatus was an L-shaped runway consisting of a 10-in. startbox, a 36-in. alleyway, and a 13-in. goalbox. The apparatus was made of $3 / 4$-in. plywood and was 3 in. wide and 5 in. high throughout. Guillotine doors separated the startbox from the alley and the alley from the goalbox. The arm of the L-shaped goalbox was 9 in. long. Noyes food pellets $(.045 \mathrm{~g})$ were available to $S$ in a plastic cup located at the end wall of the arm of the $L$ and behind the delay door. The horizontal

Fig. 1. Mean running speeds in blocks of eight trials during extinction.

nature of simultaneous manipulation of $D$ length and reward magnitude on I trials necessitated a confounding of $D$ length with the variable of successive reward magnitudes. While the 2.8 pellet and $8-2$ pellet transitions were held constant for

sliding delay door was located 3 in. in front of the end wall. The entire apparatus was painted flat black. It was covered with 1/8-in. Plexiglas and illuminated by $7-W$ bulbs suspended 20 in. above the Plexiglas.

Start times were measured from the opening of the startbox door to the breaking of a photobeam 3 in. distant. Running times were measured from the breaking of the beam 3 in. distant from the startbox door to the interruption of a second beam 36 in. distant. The delay interval of $15 \mathrm{sec}$ was timed from the interruption of the second beam.

\section{EXPERIMENTAL DESIGN \\ AND PROCEDURE}

The basic design was a 2 by 2 factorial with two levels of D length (1 vs 1 and 3 ) and two levels of reward magnitude on immediately rewarded (I) trials ( 2 vs 8 pellets). The groups were designated $8 \mathrm{D}(1)$, $8 D(1-3), 2 D(1)$, and $2 D(1-3)$, where the first number represents the magnitude of reward on I trials and the number in parentheses refers to the D length. All Ss received two pellets on delayed trials. The 2-day sequence of D and I trials for the groups receiving D length of one was DIII and DIDD. This sequence was repeated throughout the entire experiment. For the D length of one and three, the sequence was IIDI and DDDI. The methodological consisted of 32 trials in which $S$ was

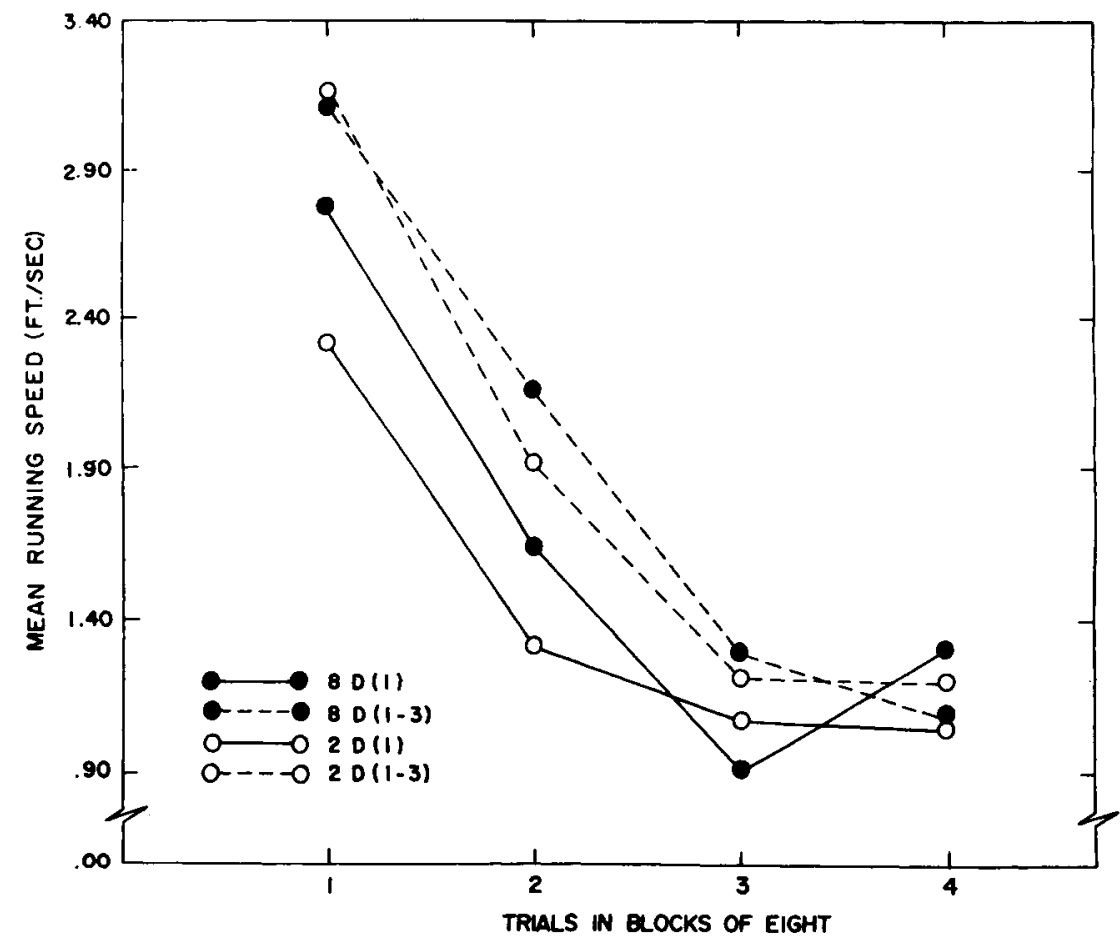


detained in the goalbox for $20 \mathrm{sec}$, with the sliding delay door closed. The intertrial interval was approximately $30 \mathrm{sec}$.

\section{RESULTS}

Acquisition

Analyses of variance were performed on start speeds $(\mathrm{ft} / \mathrm{sec})$ and running speeds ( $\mathrm{ft} / \mathrm{sec}$ ) over acquisition in blocks of eight trials. The analysis of variance design incorporated reward magnitude on I trials, $D$ length, blocks and replications. ${ }^{2}$ The results of these analyses indicated that: (1) neither the reward magnitude on I trials nor the D length had a statistically significant effect on start or running speeds $(\mathrm{F}<1)$; (2) the blocks effect was significant for both start speeds and running speeds $(\mathrm{F}=160.42$ and 274.76 , $\mathrm{df}=7 / 385$, respectively, $\mathrm{p}<.01$ ); and (3) the Reward Magnitude on I Trials by $D$ Length interaction was statistically reliable for start speeds $(F=7.06$, $\mathrm{df}=1 / 55, \mathrm{p}<.05)$ but not for running speeds $(F=3.83, d f=1 / 55, p>.05)$. To evaluate the interaction, separate $t$ tests were performed and indicated that Group $8 D(1)$ ran significantly faster $(\mathrm{t}=4.85, \quad \mathrm{df}=30, \mathrm{p}<.01)$ than Group 8D(1-3), and that Group 2D(1-3) ran substantially faster $(t=3.00, d f=29$, $\mathrm{p}<.01)$ than Group 2D(1).

Extinction

Analysis of variance was performed on start speeds $(\mathrm{ft} / \mathrm{sec})$ over blocks of eight trials. The results of these analyses indicated that magnitude of reward on I trials was not a relevant factor $(F=1.80$, $\mathrm{df}=1 / 55, \mathrm{p}>.05)$. The $\mathrm{D}$-length variable also failed to affect start speeds during extinction $(F<1)$. The blocks effect was significant beyond the .01 level $(F=72.37$, $\mathrm{df}=3 / 165$ ), and the Reward Magnitude on I Trials by $D$ Length interaction failed to be statistically significant $(\mathrm{F}<1)$.

Fig. 1 presents the mean running speeds as a function of trial blocks. As may be seen in Fig. 1, the groups receiving the longer $D$ length were most resistant to extinction. Analyses of variance performed on running speeds ( $\mathrm{ft} / \mathrm{sec}$ ) over blocks of eight trials revealed that the longer $D$ length produced a significantly greater resistance to extinction $(F=5.73$, $\mathrm{df}=1 / 55, \quad \mathrm{p}<.05)$. The Reward Magnitude on I Trials by D Length interaction failed to achieve statistical reliability $(F<1)$. The blocks effect was statistically reliable $(F=145.15$, $\mathrm{df}=3 / 165, \mathrm{p}<.01$ ) as well as the Blocks by $D$ Length interaction $(F=4.93$, $\mathrm{df}=3 / 165, \mathrm{p}<.01$ ).

\section{DISCUSSION}

The extinction data lend support to the findings of Capaldi (1967a) in that $D$ length was a significant determiner of resistance to extinction. A most critical finding of the study, however, was that the increased reward magnitude on I trials was not sufficient to reflect differences in extinction. Refutation of Capaldi, Godbout \& Downs' (1968) results cannot be claimed because of the difference in levels of reward magnitude. While the present study used 2 and 8 pellets, Capaldi et al used 2 and 24 pellets. The failure of Group 8D(1-3) to run faster than Group 2D(1-3) during extinction might, therefore, be explained on the basis that, with irregular schedules of partial delay, conditioning of $S^{D}$ persisting from preceding $\mathrm{D}$ trials necessitates relatively large reward magnitude on I trials.

\section{REFERENCES}

CAPALDI, E. J. Sequential versus nonsequential variables in partial delay of reward. Journal of Experimental Psychology, 1967a, 74, 161-166. CAPALDI, E. J. A sequential hypothesis of instrumental leaming. In K. W. Spence and $J$. T. Spence (Eds.), The psychology of learning and motivation: Advances in research and theory. Vol. 1. New York: Academic Press, 1967b. Pp. 67-156.

CAPALDI, E. J. GODBOUT; R. C., \& DOWNS, B. Joint effects of magnitude of immediate reward and magnitude of delayed reward on acquisition and extinction. Psychonomic Science, 1968, 13, 277-278. NOTES

1. The authors wish to thank Neil H. Cohn for his assistance.

2. The replications factor was significant throughout both the acquisition and extinction data. Since the interactions of replication with reward magnitude on I trials and also with $D$ length was not significant, the replications data was not reported in the present study.

\section{Training schedules and the E-effect on the acquisition of a two-turn task in a temporal circular maze}

HEATHER MOHAY $Y^{1}$ and CHIA-SHONG CHEN, Monash University, Melbourne, Australia

Eighteen male and 18 female hooded rats were trained to perform a two-turm task in a temporal circular maze to evaluate the effects of different training schedules on acquisition rate. Ss were randomly allocated to the two Es (HM and CSC), and also to one of three training schedules: (1) $4 \times(2 G 2 F)$, i.e., four repetitions of two guided trials followed by two free trials; (2) $2 \times(4 G 4 F)$; (3) $1 \times(8 G 8 F)$. At the termination of the experiment, a mareked, and quite unexpected, E-effect was noted, HM's Ss learning in significantly fewer trials than CSC's Ss. An attempt was made to trace the mediating factors; the only consistent differences that could be found existed in the manner of handling the $S s$ in the initial stages, i.e., before pretraining. Significant differences were also found between the different training schedules used, learning occurring more slowly on the $1 \times(8 G 8 F)$ schedule than on either of the other two.

This experiment was designed to study a hypothesis suggested by Chen (1967): the pattern of guided and free trials is of greater importance than the overall number of these trials in the acquisition, by rats, of a two-turn task in a temporal circular maze. At the conclusion of this experiment, it was noted that there existed a very strong $E$ effect on the rate of acquisition. A similar E-effect phenomenon has been reported by Rosenthal et al $(1963,1964)$, in both discrimination learning and operant learning situations, and by Brogden (1960), in an avoidance learning situation.

\section{SUBJECTS}

Eighteen male and 18 female experimentally naive hooded rats from the Monash University colony, aged 60-70 days at the commencement of the experiment, were housed individually, with ad lib water, and maintained at approximately $80 \%$ estimated growth weight throughout the experiment. Nine male and nine female Ss were allocated randomly to each of the two Es, and within these two subgroups Ss were randomly allocated to one of three training schedules after the completion of the preliminary training (see Procedure below).

\section{APPARATUS}

Figure 1 shows the ground plan of the maze, a detailed description of which is available elsewhere (Chen, 1967). In this maze situation, $S$ was required to make two complete circuits of the circular runway, in the same direction, before reentering the stem; if more or less than the required number of circuits was made the trial was counted as an error and the reward (one 50-mg pellet), which was given at the end of every correct trial, was withheld. A trial was defined as at least one complete circuit of the circular runway 